\title{
THE INSTITUTE OF ACTUARIES.
}

\author{
EXAMINATIONS, 1909.
}

We are authorized to state, for the information of Candidates entering for the Examinations to be held in 1909, that Candidates who have passed Part I only of any previous Syllabus will be permitted to take Section (3) of the new Part I, as a separate Examination; also, that the paper set in that Section (Compound Interest and Annuities-Certain) will in 1909 be common to the old Part II and the new Part I; and that the Board of Examiners in that year will report separately as to the Candidates in Part II who pass in that Section.

The Council have appointed the undermentioned gentlemen to constitute the Board of Examiners until further notification :Messrs. Thomas G. Ackland (Chairman, 1909), Henry J. Baker (Hon. Secretary, 1909), Arthur R. Barrand, Joseph Burn, W. Palin Elderton, George King, John Spencer, Robert R. Tilt, Harold M. Trouncer and Alfred W. Watson.

\section{OBITUARY NOTICE.}

\section{Dr. Israel C. Pierson.}

We regret to announce the death of Dr. Israel C. Pierson, which took place on September 11th last. Dr. Pierson was the first Secretary of the Actuarial Society of America, a post which he held for ten years, during which period he very largely contributed to its growth and development. Those who attended the meetings of the Fourth International Congress of Actuaries held at New York in 1903, will have pleasant recollections of the dignity and courtesy with which Dr. Pierson presided over its sessions, and of his cordial relations with the delegates from Great Britain and other countries, both in the business meetings and in the social engagements of the Congress. He was elected a corresponding member of the French Institute of Actuaries, and of the Belgian Association of Actuaries, and was an honoured Associate of our own Institute. He was a Graduate of the New York University, from which he received the degree of $\mathrm{Ph.D}$. in 1890. He was also a Fellow of the American Statistical Society, the New York Academy of Science, and the New York Mathematical Society. He received his actuarial training in the New York Life Insurance Company, and the Equitable Life Assurance Society of the United States, and was Actuary of the Washington Life Office until his resignation in 1905. 